\title{
Use of national food balance data to estimate the adequacy of zinc in national food supplies: methodology and regional estimates
}

\author{
Sara E Wuehler*, Janet M Peerson and Kenneth H Brown \\ Department of Nutrition and Program in International Nutrition, University of California-Davis, One Shields Avenue, \\ Davis, CA 95616, USA
}

Submitted 8 September 2004: Accepted 18 January 2005

\begin{abstract}
Objectives: Adequate zinc nutriture is critically important for human health, but the development of programmes to control zinc deficiency is limited by the lack of reliable information on population zinc status. The present analyses were conducted to: (1) estimate the absorbable zinc content of national food supplies; (2) compare this information with theoretical population requirements for zinc; and (3) use these results to predict national risks of inadequate zinc intake.

Setting and design: National food balance data were obtained for 176 countries from the Food and Agriculture Organization of the United Nations. The amount of absorbable zinc in these foods was estimated from food composition data, and zinc absorption was predicted using a model developed by the International Zinc Nutrition Consultative Group (IZiNCG). Demographic data were obtained from United Nations estimates, and age- and sex-specific physiological requirements for absorbable zinc were estimated using IZiNCG recommendations.

Results and conclusions: The mean per capita absorbable zinc content of national food supplies ranged from $2.98-3.01 \mathrm{mg} \mathrm{day}^{-1}$ in Western Europe and USA \& Canada to $2.09 \mathrm{mg} \mathrm{day}^{-1}$ in Southeast Asia. The estimated percentage of individuals at risk of inadequate zinc intake ranged from $9.3-9.5 \%$ in the regions of North Africa \& Eastern Mediterranean and USA \& Canada to $33.1 \%$ in Southeast Asia. Overall, approximately $20.5 \%$ of the world's population is estimated to be at risk of inadequate zinc intake. Data on the absorbable zinc content of national food supplies can be used to determine whether further assessments of population zinc status and development of intervention programmes are warranted.
\end{abstract}

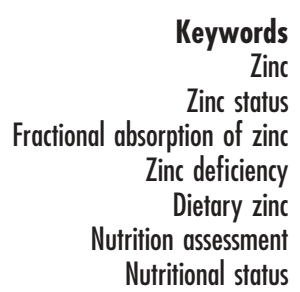

Zinc is an essential nutrient that is critical for normal growth, immune function, neurobehavioural development and pregnancy outcome ${ }^{1}$. Results of multiple community-based intervention trials in lower-income countries indicate that zinc supplementation increases the growth of stunted children ${ }^{2}$, decreases morbidity from infectious diseases ${ }^{3,4}$ and may reduce child mortality ${ }^{5}$. Thus, intervention programmes are needed to control zinc deficiency in high-risk populations, and better information regarding population zinc status is required for programme planning and targeting of resources.

The risk of zinc deficiency in a population can be assessed using either direct indicators of zinc status ${ }^{6}$ or suggestive information based on ecological factors that influence zinc nutriture. The major direct indicator of population zinc status is the distribution of serum zinc concentrations in a representative sample of the population. However, these assessments are fairly costly and logistically challenging, and they have been conducted in only a small number of countries. Pending the availability of more information from direct assessments of population zinc status, information on the amount of total and absorbable zinc in national food supplies could be used as suggestive evidence of the adequacy of zinc intake in respective populations. The remarkable advantage of this latter information is that relevant data are collected routinely in most countries and reported to the Food and Agriculture Organization of the United Nations (FAO). Thus, the risk of zinc deficiency due to inadequate amounts of absorbable zinc in the food supply can be estimated with little additional cost or effort.

The objectives of the present study were to estimate the amount of zinc in national food supplies, and to estimate the global risk of dietary inadequacy by comparing the amount of absorbable zinc available in the national food supplies with the respective populations' theoretical mean physiological requirements. This paper describes the methods used to achieve these objectives and the resulting 
estimates of national, regional and global risks of inadequate zinc intake. A preliminary paper describing this approach was published previously ${ }^{7}$, and a brief summary of the results was included in a recent technical document prepared by the International Zinc Nutrition Consultative Group (IZiNCG) ${ }^{1}$. The current paper differs from the earlier presentations in several important ways, as follows:

- We have updated the food balance sheet data for the period 1992-2000;

- We are using a new model for estimating fractional absorption of zinc from full-day studies of mixed diets and new estimates for the mean physiological zinc requirements; and

- We have included additional analyses using several different assumptions about the effects of local processing and fermentation of wheat and maize on the estimated absorption of zinc.

\section{Methods}

The following steps were undertaken to complete the analysis for each country represented in the FAO database:

1. Compilation of data on the average daily per capita availability of foods, expressed in kcal;

2. Calculation of the zinc and phytate contents of these foods;

3. Estimation of the absorbable zinc content of the daily food supply;

4. Calculation of the theoretical mean daily per capita physiological requirement for zinc, based on the age and sex distribution of the national population;

5. Comparison of the absorbable zinc content of the food supply with the population's theoretical mean physiological requirement; and

6. Estimation of the percentage of the population at risk of inadequate zinc intake.

Each of these steps is described in the following paragraphs.

\section{Average daily per capita availability of foods}

The FAO publishes national food balance sheets (FBSs) annually for all participating countries. These balance sheets provide the sum of all food stocks, imports and production, less exports and losses to manufacturing, storage or other uses. We downloaded an annual average for the 176 countries with available information for the period from 1992 to $2000^{8}$. When data were not presented for all years in a particular country (e.g. Afghanistan, Czech Republic, Slovakia, Ethiopia and Ethiopia PDR), weighted averages were calculated using relevant available information.

\section{Calculation of zinc and phytate contents of foods}

To produce globally uniform national balance sheets, the FAO combines reported foods into 95 'standardised' food commodities by aggregating similar foods into one food group and by reverting processed foods back to the original food. For example, in the first standardisation method, chicken, duck and turkey are included in one commodity labelled 'poultry', while in the second standardisation method the wheat flour used to make bread, pasta and crackers is reported as the original food, 'wheat'. The FAO provides a list of foods that might be combined into the aggregated commodities, but the national FBSs do not indicate the proportions contributed by individual foods. Moreover, the type and extent of processing applied to foods, such as wheat, are also not reported on FBSs.

Following detailed review, we discovered that most of the foods included in each of the FAO aggregated food commodities had similar contents of phytate and zinc. Therefore, with just two exceptions, zinc and phytate levels were assumed to be the mean of these values from all appropriate foods. The two exceptions were oysters and molasses (included in the commodities 'crustaceans' and 'sweeteners', respectively), which are very high in zinc relative to other foods in their categories and likely to be available in relatively small amounts compared with other foods in the same categories. Therefore, the nutrient values for these two foods were not included when calculating the mean nutrient contents of their respective food categories.

The zinc and phytate contents of the major food commodities were obtained from the WorldFood System International Mini-list ${ }^{9}$ and the US Department of Agriculture Nutrient Database ${ }^{10}$. Because of the standardisations just described, the nutrient values were multiplied by the daily per capita caloric value of these foods in the national FBSs rather than on a weight basis (i.e. mg zinc/ kcal).

Because whole-grain cereals generally provide more zinc and phytate than refined flours and fermentation and/or soaking can reduce their phytate content, we attempted to locate country-specific data on cereal processing. Regrettably, relevant documentation is generally lacking. Therefore, to estimate the amounts of zinc and phytate available in food supplies, we developed regional assumptions about the proportions of cereals that are consumed as whole grains or processed flours based on information solicited from international research centres $^{11}$ and located in published documents ${ }^{12,13}$. In particular, we assumed that rice is universally consumed as milled white rice and all other cereals except wheat and maize are available as unprocessed unfermented whole grains. The assumptions regarding wheat and maize are summarised by region in Table 1 . In most regions it was assumed that wheat is consumed as in the USA: $99 \%$ as white flour and $1 \%$ as whole wheat; $58.5 \%$ of white flour 
(75\% extraction) is fermented with yeast, whereas no whole wheat is fermented ${ }^{13}$. Because a very limited number of foods are fortified with zinc in just a few countries, we did not make any allowances for fortification.

Because of the uncertainty of these estimates, we completed a second set of analyses in which we applied two alternative sets of assumptions. The purpose of these alternative assumptions was to provide a likely range of absorbable zinc in the food supply of various regions. These ranges are presented in Table 1 as 'lower estimated zinc absorbability' and 'higher estimated zinc absorbability'.

\section{Estimation of absorbable zinc content of foods}

In our original calculations of the amount of absorbable zinc available in national food supplies ${ }^{7}$, we applied estimates of the fractional absorption of zinc (FAZ) by using a model proposed by the World Health Organization (WHO), which was based mostly on single-meal studies ${ }^{14}$. Since that model was published, a number of full-day studies have been conducted to assess absorption of zinc from mixed diets. Therefore, in the current paper, we applied a new prediction model for FAZ that was prepared by the IZiNCG using all of the newly available data ${ }^{1}$. The main differences between the previously used WHO model and the new IZiNCG prediction model are:

- The new model uses a logit transformation of fractional absorption of zinc, thus guaranteeing a predicted value between 0 and 1 , rather than the log transformation used by the original WHO model; and

- As stated above, the new model uses data from full-day studies (in both males and females consuming typical mixed diets) rather than data derived primarily from single-meal studies.

\section{Calculation of the theoretical mean population requirement for absorbed zinc}

Because new information is available for estimating zinc requirements, we used the latest age- and sex-specific estimated average physiological requirements developed by IZiNCG ${ }^{1}$ to calculate the national theoretical mean daily per capita physiological requirement for absorbed zinc, hereafter referred to as the 'mean physiological requirement'. To do so, the estimated average physiological requirements for zinc in each age and sex grouping were weighted according to the national population distributions for 1995, which are available from the United Nations ${ }^{15}$. Population distributions were not available for 15 countries for which FBSs were obtained, so a mean regional population distribution was used in the calculations for these countries. No adjustments of requirements were made for pregnancy or lactation. 


\section{Estimating the percentage of the population at risk of inadequate zinc intake}

We first compared the estimated absorbable zinc content of national food supplies with the national requirement to calculate the percentage of the mean physiological requirement for zinc that is available in the food supply. Next, to estimate the percentage of the population at risk of inadequate zinc intake, we applied a method akin to the Estimated Average Requirement (EAR) cut-point method described by the Institute of Medicine ${ }^{16}$. This method assumes that the proportion of the population with intakes less than the mean physiological requirement is about the same as the proportion of the population whose intakes are below their actual requirements. Thus, to estimate the percentage of the population for whom access to absorbable zinc is less than their actual requirements, we assumed that intake of absorbable zinc from the available food supply follows a normal distribution with the mean set at the daily mean per capita amount of absorbable zinc available. Few countries have conducted nationally representative food consumption surveys from which inter-individual variations of intake can be calculated. Therefore, we assumed a $25 \%$ inter-individual coefficient of variation (CV) in zinc intake, as suggested previously by WHO, based on limited information from a national nutrition survey reported in the UK in $1990^{14,17}$. We also examined the impact of assuming inter-individual CVs of $20 \%$ or $30 \%$.

\section{Results}

National data for the total per capita amount of zinc, phytate and absorbable zinc available in the food supply are summarised by geographical region in Table 2. Also shown are data on the per capita absorbable zinc, expressed as a percentage of the mean physiological requirement for zinc, and the estimated percentage of the population at risk of inadequate zinc intake, assuming an inter-individual CV of intake of $25 \%$. The regional results are presented in descending order according to the daily per capita amount of absorbable zinc that is available in national food supplies. As indicated in the table, the amount of absorbable zinc in national food supplies is greater in the more industrialised countries of Western Europe and USA \& Canada than in the lower-income countries of South Asia, Southeast Asia and Sub-Saharan Africa. Country-specific results of the percentage of the population at risk of inadequate zinc intake due to inadequate zinc in the food supply are generally consistent within regions (Fig. 1) when countries are categorised into $<15 \%, 15-25 \%$ and $>25 \%$ of individuals at risk.

As indicated in Table 2, the global food supply provides a weighted average of $\sim 131 \%$ of the national requirements. Assuming a $25 \%$ inter-individual variation in habitual intakes, an estimated $20.5 \%$ of the world's population is at risk of inadequate zinc intake. This risk ranges from $\sim 9 \%$ in

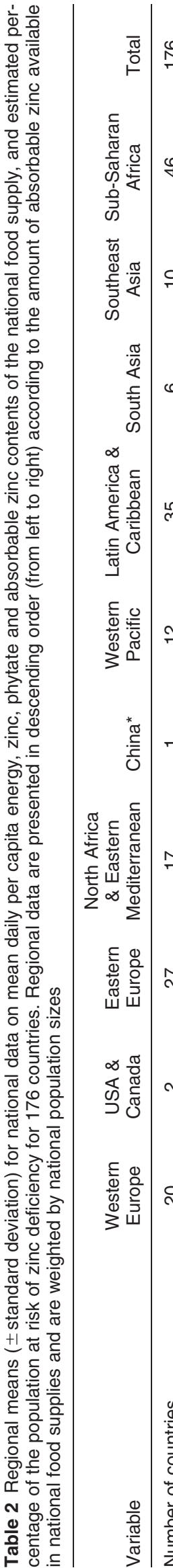

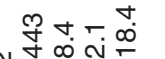

ข

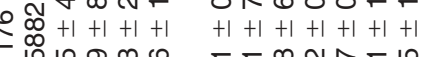

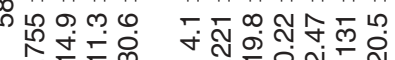
Aั耳TO

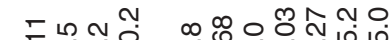

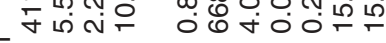
$0-\infty+1+1+1+1+1+1+1+1+1+1$ సั่ 过 $+1+1+1+1+1+1+1$

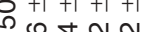

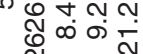

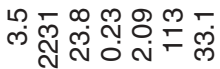

8 เก 0 ब्ले+1+1+1 +1

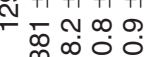

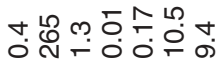
$+1+1+1+1+1+1+1$ 次灾

$$
\text { 승 ㅇํㅁำ }
$$

$\rho \stackrel{\infty}{\infty}+1+1+1+$

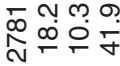

+

Oก, $+1+1+1+1+1+1+1$

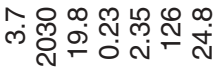

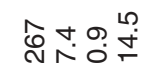

$\simeq \widetilde{N}+1+1+1+1$

$\begin{array}{lll}+1 & +1 \\ 0 & 0 & 0 \\ 0 & 0\end{array}$

๓ $+1+1+1+1+1+1+1$

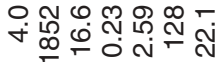

○ㅇํㅇㅇㅇ

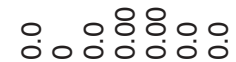

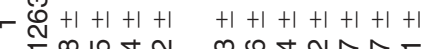

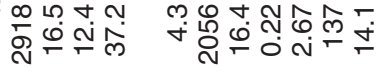

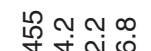

$2 \frac{1}{2}+1+1+1+1$

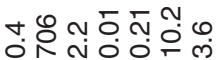

$+1+1+1+1+1+1+1$

மم)

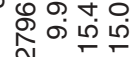

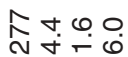

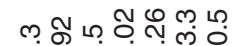

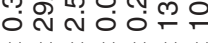
ล $\frac{\infty}{2}+1+1+1+1 \quad+1+1+1+1+1+1+1$

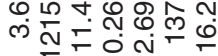

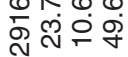

은 웅

ㄷ. $08 \%$ เ

0 约०0 $\sim 200+1+1+1+1+1+1+1+1+1+1$

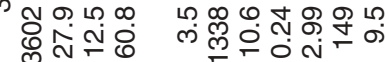

운 욤

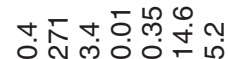
$8 \sqrt{5}+1+1+1+1 \quad+1+1+1+1+1+1+1$

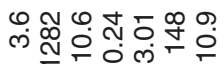

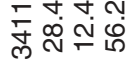




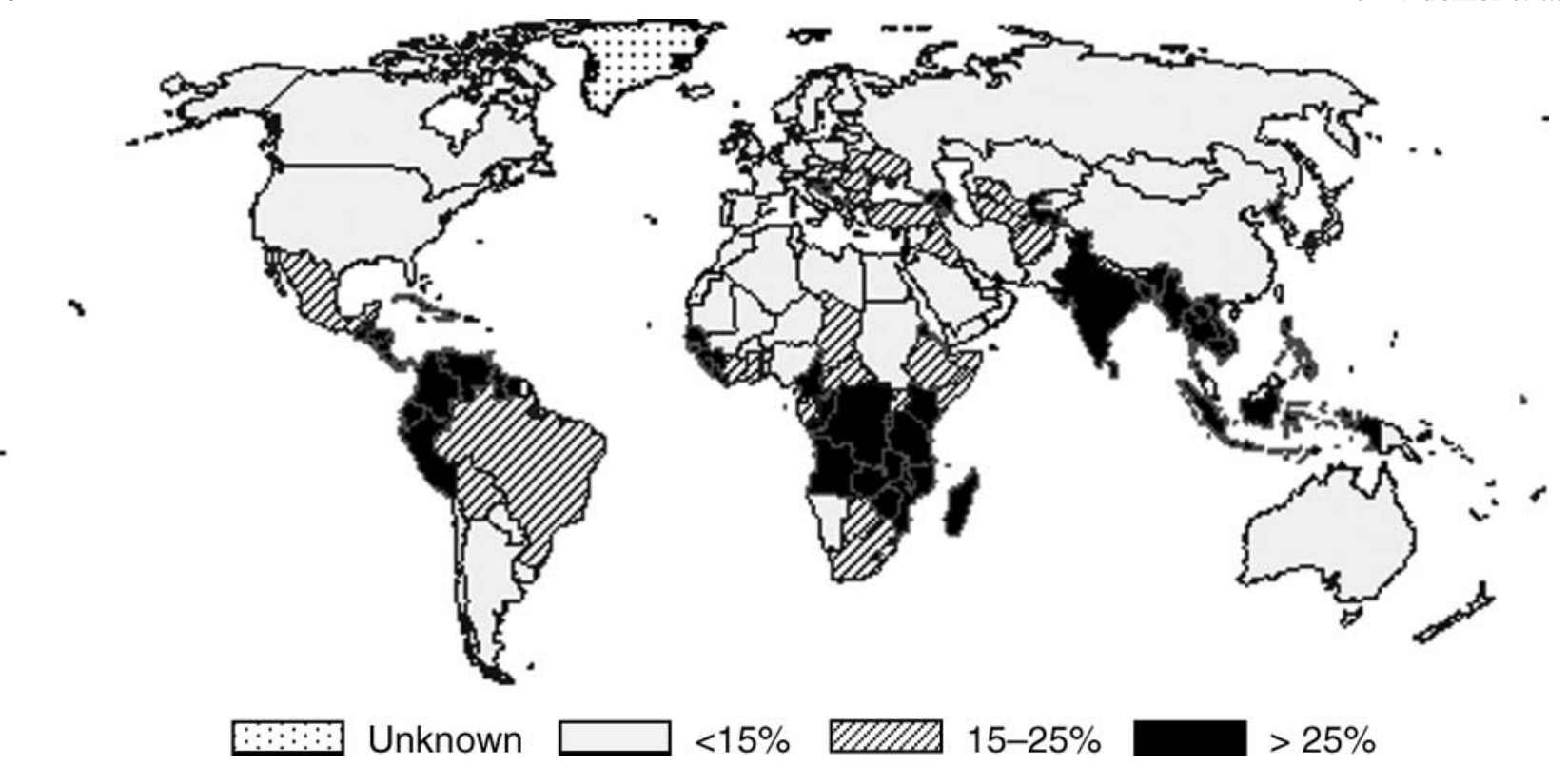

Fig. 1 Risk of inadequate intake of zinc, based on absorbable zinc content of national food supply and estimated requirements from the International Zinc Nutrition Consultative Group

the regions of Eastern Mediterranean \& North Africa and USA \& Canada to $\sim 33 \%$ in Southeast Asia. There were a few noteworthy regional changes in these results when different assumptions about the processing of wheat and maize were applied (Table 3). The regions with the largest changes in estimated risk of zinc deficiency were Eastern Mediterranean \& North Africa (which changed from 7.4\% when the assumption of 'higher estimated zinc absorbability' was applied to $14.6 \%$ when the assumption of 'lower estimated zinc absorbability' was applied) and South Asia

Table 3 Effect of different assumptions ${ }^{*} \dagger$ concerning food processing on regional estimates of absorbable zinc content of national food supplies (as \% of mean physiological requirement) and percentage of the population at risk of inadequate zinc intake. Estimates were left blank where assumptions regarding food processing were not changed

\begin{tabular}{|c|c|c|c|c|c|c|}
\hline & \multicolumn{3}{|c|}{$\%$ mean physiological requirement } & \multicolumn{3}{|c|}{$\%$ at risk } \\
\hline & \multirow[b]{2}{*}{$\begin{array}{c}\text { Initial } \\
\text { estimate }\end{array}$} & \multicolumn{2}{|c|}{ Assumption } & \multirow[b]{2}{*}{$\begin{array}{l}\text { Initial } \\
\text { estimate }\end{array}$} & \multicolumn{2}{|c|}{ Assumption } \\
\hline & & $\begin{array}{l}\text { Lower estimated } \\
\text { zinc absorbability* }\end{array}$ & $\begin{array}{l}\text { Higher estimated } \\
\text { zinc absorbability } \dagger\end{array}$ & & $\begin{array}{l}\text { Lower estimated } \\
\text { zinc absorbability* }\end{array}$ & $\begin{array}{l}\text { Higher estimated } \\
\text { zinc absorbability } \dagger\end{array}$ \\
\hline Western Europe & 148.4 & - & 148.7 & 10.9 & - & 10.8 \\
\hline USA \& Canada & 149.0 & - & 149.1 & 9.5 & - & 9.5 \\
\hline Eastern Europe & 136.5 & - & 136.8 & 16.2 & - & 16.1 \\
\hline $\begin{array}{l}\text { North Africa \& Eastern } \\
\text { Mediterranean }\end{array}$ & 151.5 & 137.9 & 159.3 & 9.3 & 14.6 & 7.4 \\
\hline China & 136.7 & - & 136.8 & 14.1 & - & 14.1 \\
\hline Western Pacific & 127.7 & - & 127.8 & 22.1 & - & 22.0 \\
\hline $\begin{array}{l}\text { Latin America, except } \\
\text { Central America }\end{array}$ & 127.3 & 126.9 & 129.4 & 24.2 & 24.9 & 22.9 \\
\hline Central Americał & 120.7 & 119.9 & 125.3 & 26.3 & 27.0 & 22.5 \\
\hline South Asia & 120.1 & 112.7 & 124.0 & 26.7 & 33.7 & 23.8 \\
\hline Southeast Asia & 112.9 & - & 112.9 & 33.1 & - & 33.0 \\
\hline $\begin{array}{l}\text { Sub-Saharan Africa, except } \\
\text { West Africał }\end{array}$ & 113.1 & 112.6 & 115.0 & 34.6 & 35.1 & 32.6 \\
\hline West Africa & 132.7 & 131.5 & 132.9 & 17.9 & 18.7 & 17.8 \\
\hline
\end{tabular}

*Estimates based on assumptions of lower zinc absorbability: (1) all countries in Latin America and Sub-Saharan Africa, $1 \%$ whole wheat (no fermentation) and $99 \%$ white wheat flour (58.5\% fermented); (2) North Africa \& Eastern Mediterranean and South Asia, $50 \%$ whole wheat (no fermentation) and $50 \%$ extracted white flour (58.5\% fermented); (3) West Africa, $50 \%$ of maize processed (by fermentation); and (4) all other assumptions unchanged.

$\dagger$ Estimates based on assumptions of higher zinc absorbability: (1) North Africa \& Eastern Mediterranean and South Asia, 95\% of wheat is whole wheat (25\% fermented) and 5\% extracted wheat flour (58.5\% fermented); (2) all other regions, $58.5 \%$ of all whole wheat fermented; (3) Latin America \& Caribbean and Sub-Saharan Africa, except Central America and West Africa, $50 \%$ of maize is fermented; (4) Central America, $50 \%$ of maize processed to tortillas; and (5) all other assumptions unchanged.

† Region split to account for different assumptions regarding food processing within region. 
(which changed from 23.8 to $33.7 \%$ when the same respective assumptions were used).

The estimated proportion of absorbable zinc available by food group is depicted in Fig. 2, and the regions are ordered, highest to lowest, by the total amount of absorbable zinc available in the food supply. In general, there is a strong positive relationship between the proportion of zinc available from animal source foods and the total amount of absorbable zinc available in the food supply ( $r=0.76$ ) (Fig. 2a) and a corresponding negative relationship with the risk of inadequate zinc intake $(r=-0.55)$. However, this latter relationship does not seem to be consistent in the region of Eastern Mediterranean \& North Africa, where the proportion of zinc from animal sources is low (9.9\%, Table 2) but the proportion of the population at risk of inadequate zinc intake is also low (9.3\%). The proportion of zinc provided by wheat in this region is the highest of any region (Fig. 2b) and the proportion of energy derived from wheat is also highest in this region (data not shown).

\section{Discussion}

Using routinely collected national food balance data and international food composition databases, it was possible to compile data on the average daily per capita availability of foods and dietary zinc in 176 countries during the period 1992-2000, and estimate the percentage of the population at risk of inadequate zinc intake. With this information, we have classified individual countries and regions according to the level of risk that the national food supply is inadequate to meet the population's physiological requirements for zinc. Results of all country-specific data, regional designations, nutrient values applied to each food commodity and models for assessing the fractional absorption of zinc are now available in a technical document prepared by IZiNCG ${ }^{1}$.

The resulting new $20.5 \%$ estimate for the global risk of inadequate zinc intake is considerably lower than our previous estimate of $48.9 \%{ }^{7}$. The modification of the current estimate is due to the methodological differences since the original analyses. Specifically, the present estimates: rely on more extensive, updated information regarding the physiological requirements for zinc; and reflect the results of more recent studies that allow estimates of the FAZ in full-day mixed diets rather than single meals. In addition, the current estimates include more specific regional assumptions about the processing of wheat and maize. Because of instability in the estimated risks, considerable caution is warranted in interpretation

(a)

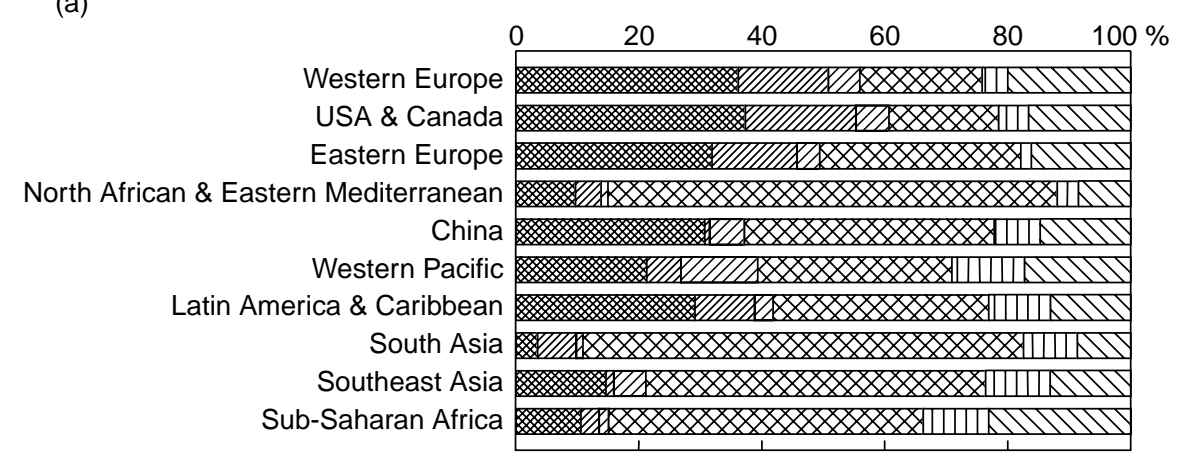

Meat Dairy $\square \Delta$ Other animal $\otimes$ Cereals $\square$ Legumes $\square$ Other

(b)

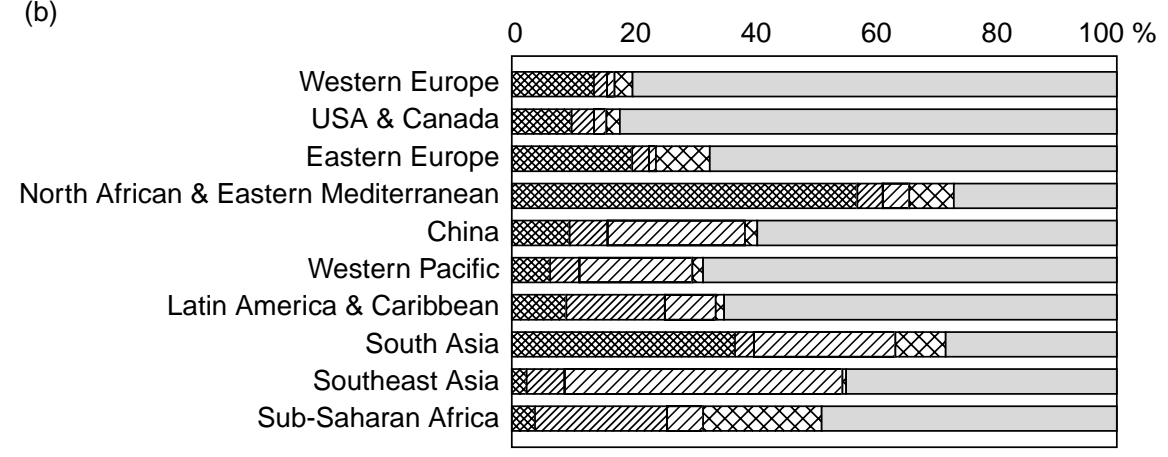

Wheat $\square$ Maize $\square$ Rice $\square$ Other cereals $\square$ Non-cereals

Fig. 2 Percentage of total zinc in national food supplies derived from various sources, by geographic region, weighted by population size and listed in descending order according to the per capita amount of absorbable zinc available: (a) food sources and (b) cereal and noncereal sources 
of the absolute risk figures. Nevertheless, despite the changes in the revised absolute risk estimates, it is important to note that the country-specific rank order of risk is highly conserved across both sets of estimates when assumptions regarding processing of grains are kept constant. In particular, when we compared the WHO method of estimating absorbable zinc with the IZiNCG method, the Spearman correlation of country rank order was $0.972(P<0.0001)$. Thus, individual countries should be able to draw inferences regarding their relative likelihood of having a public health problem of zinc deficiency compared with other countries.

Although the relationship between zinc from animal source foods and the total amount of absorbable zinc available in the food supply is generally consistent across regions (Fig. 2a), the form and amount of wheat that is available seem to be independent predictors of the amount of absorbable zinc that is available in a region. In the regions North Africa \& Eastern Mediterranean and South Asia, where the relationship between zinc from animal sources and the amount of absorbable zinc available is the most inconsistent (Fig. 2a and Table 2), wheat contributes a relatively high proportion of total energy to the food supply (data not shown). For these regions, we assumed that $90 \%$ of the wheat is available as whole wheat, which has considerably more zinc than refined wheat flour. Although the phytate content of whole wheat is also greater than in refined flour, the net impact of the assumption that a greater proportion of wheat is consumed as whole wheat is to increase the estimated amount of absorbable zinc that is available. Thus, in regions such as North Africa \& Eastern Mediterranean and South Asia, where wheat is a large contributor to the available energy, our assumption that $90 \%$ of this wheat is available as whole wheat has a relatively large impact on the estimated amount of absorbable zinc available. The broad range of results in relation to the type of food processing in these regions (Table 3) demonstrates how errors in these assumptions can affect these analyses. There was relatively little impact of the different assumptions regarding cereal processing in other regions because wheat forms a smaller proportion of their national food supplies and the range of assumptions regarding maize processing has a less dramatic effect on estimated zinc absorption from maize.

The considerable asset of this method of estimating the national risk of zinc deficiency is the number of countries for which FBSs and population demographics are routinely collected and currently available. Results of the present analyses thus can be used to assess the need for further study or for development of intervention programmes to control zinc deficiency in settings where the risk is considered sufficiently great to warrant immediate action. Nevertheless, there are a number of potential limitations of this method that need to be recognised. Some of these are:
- Possible inaccuracies in the national food balance data reported to the FAO;

- Errors in the estimated nutrient contents when individual foods are standardised into uniform food commodities on the balance sheets;

- The lack of country-specific information on food processing or fortification;

- Inaccuracies due to use of a universal food composition database rather than country-specific data;

- Inadequate information about the size of meals, the type of food consumed at each meal and hence the resulting estimated availability of absorbable zinc from whole diets; and

- Uncertainties in the actual country-specific, interindividual variation of dietary zinc intakes.

In addition, although we applied an updated method for assessing the FAZ and for estimating theoretical zinc requirements, data are still very limited to validate these estimates, especially for assessing the zinc adequacy of high-phytate diets, and further studies are warranted.

Our estimation of the percentage of the population at risk of inadequate zinc intake was based on an analysis akin to the EAR cut-point method described in the Institute of Medicine's publication on Dietary Reference Intakes ${ }^{16}$. This estimation required using an assumption regarding the inter-individual variation in zinc intake because this information is not available from FBSs. In the current analyses, initially an assumption of a $25 \% \mathrm{CV}$ in interindividual differences in intake was applied ${ }^{14,17}$. We also examined the impact of assuming 20\% and 30\% interindividual $\mathrm{CVs}$ in intake, which modified the global estimates of inadequate zinc intake to $18 \%$ and $25 \%$, respectively, instead of the initial estimate of $20.5 \%$. Notably, these different estimates do not affect the rank order of risk by country.

Although the true population CV may be greater when considering variation across age and sex groups, for the present analyses it was necessary to assume that the ratio of intake to requirements is the same for each age and sex group and that the within-group correlation between intake and requirements is reasonably low. These assumptions can be questioned, so they should be tested empirically once dietary datasets containing information on zinc and phytate intakes become available for all age and sex groups in different national samples. In cases where national data are already available on food composition, food processing and actual inter-individual variation in zinc intake, this information should be used locally to update the current estimates.

In acknowledging the limitations of using a method akin to the EAR cut-point method to calculate the percentage of the population at risk of zinc deficiency, we also recognise that - in the absence of more data - the assumptions required for use of this method generally seem to be satisfied in the case of zinc. These assumptions are: 
1. Intakes and requirements are independent within age and sex groups;

2. The requirement distribution is symmetrical around the EAR, or, in this assessment, the distribution is symmetrical around the mean physiological requirement;

3. The variance in intakes is larger than the variance of requirements; and

4. The true prevalence of inadequacy is between about 8 and $92 \%$.

Due to the limitations of this method, a nation's level of risk should be considered in combination with other possible markers of zinc deficiency, such as rates of childhood stunting ${ }^{1}$. Direct assessment of zinc status using serum zinc concentration would then be advisable in those countries where a combination of indirect markers suggests a high risk of zinc deficiency. As national surveys of the prevalence of zinc deficiency, based on direct indicators of population zinc status, become available, further efforts are needed to validate this FBS method against this information.

\section{Acknowledgement}

This work was funded by the Micronutrient Initiative of Canada, the University of California-Davis and the International Zinc Association.

\section{References}

1 International Zinc Nutrition Consultative Group; Hotz C, Brown KH, eds. Assessment of the risk of zinc deficiency in populations and options for its control. Food and Nutrition Bulletin 2004; 25: S91-204.

2 Brown KH, Peerson JM, Rivera J, Allen LH. Effect of supplemental zinc on the growth and serum zinc concentrations of prepubertal children: a metaanalysis of randomized controlled trials. American Journal of Clinical Nutrition 2002; 75: 1062-71.

3 Bhutta ZA, Bird SM, Black RE, Brown KH, Gardner JM, Hidayat A, et al. Prevention of diarrhea and pneumonia by zinc supplementation in children in developing countries: pooled analysis of randomized controlled trials. Zinc Investigators' Collaborative Group. Journal of Pediatrics 1999; 135: 689-97.

4 Bhutta ZA, Bird SM, Black RE, Brown KH, Gardner JM, Hidayat A, et al. Therapeutic effects of oral zinc in acute and persistent diarrhea in children in developing countries: pooled analysis of randomized controlled trials. American Journal of Clinical Nutrition 2000; 72: 1516-22.

5 Sazawal S, Black RE, Menon VP, Dhingra P, Caulfield LE, Dhingra U, et al. Zinc supplementation in infants born small for gestational age reduces mortality: a prospective, randomized controlled trial. Pediatrics 2001; 108: 1280-6.

6 King JC. Assessment of zinc status. Journal of Nutrition 1990; 120: S1474-9.

7 Brown KH, Wuehler SE, Peerson JM. The importance of zinc in human nutrition and estimation of the global prevalence of zinc deficiency. Food and Nutrition Bulletin 2001; 22: $113-25$.

8 Food and Agriculture Organization of the United Nations (FAO). Food balance sheets, averages for 1992-2000 [online]. Available at http://apps.fao.org/lim500/nphwrap. pl?FoodBalanceSheet\&Domain= FoodBalanceSheet. Cited: Afghanistan, 26 June 1999; all other countries, 20-24 September 2002.

9 Calloway DH, Murphy SP, Bunch S. User's guide to the International Mini-list Nutrient Database (a component of the WorldFood Dietary Assessment System). Developed under USAID Cooperative Agreement No. N-5116-A-00-2030-00. Department of Nutritional Sciences, University of California at Berkeley, Berkeley, CA, 1994.

10 US Department of Agriculture (USDA). USDA Nutrient Database for Standard Reference, Release 13 [online]. Available at http://www.nal.usda.gov/fnic/cgi-bin/ nut_search.pl. Accessed 24 August 1999.

11 Centro Internacional de Mejoramiento de Maíz y Trigo (CIMMYT) [The International Maize and Wheat Improvement Center]. Email contact to addresses accessed February 2001. Available at http://www.cimmyt.org/whatiscimmyt/ CIMContacts.htm. Received responses regarding Bangladesh, Bolivia, India, Kenya, Nepal, Uruguay and Zimbabwe.

12 Faridi H, Faubion JM, eds. Wheat End Uses Around the World. St. Paul, MN: American Association of Cereal Chemists, 1995.

13 US International Trade Commission (USITC). Industry and Trade Summary. Milled Grains, Malts, and Starches [online]. USITC Publication 3095. Washington, DC: USTIC. Available at ftp://ftp.usitc.gov/pub/reports/studies/PUB3095.PDF. Accessed 22 February 2002.

14 World Health Organization (WHO). Zinc. In: Trace Elements in Human Nutrition and Health. Geneva: WHO, 1996; 265-88.

15 WISTAT - Women's Indicators and Statistics Database (of the United Nations), Version 3 [CD-ROM]. Geneva: United Nations Publications, 1994.

16 Institute of Medicine, Food and Nutrition Board. Using the estimated average requirement for nutrient assessment of groups. Dietary Reference Intakes: Applications in Dietary Assessment. Washington, DC: National Academy Press, 2000; $73-105$.

17 Gregory J, et al. The Dietary and Nutritional Survey of British Adults. London: HMSO, 1990 (as cited in Trace Elements in Human Nutrition and Health. Geneva: WHO, 1996; Annex 2, pp. 328-9). 